\title{
Análisis de los costos de producción y la cadena de valor de las plantas tradicionales que cultivan los campesinos de
}

\section{Cundinamarca, Colombia*}

Cómo citar este artículo: Husain-Talero, S. (2018). Análisis de los costos de producción y la cadena de valor de las plantas tradicionales que cultivan los campesinos de Cundinamarca, Colombia. Cuadernos de Desarrollo Rural, 15(82), r.I8. https://www.doi.org/ı0.III44/ Javeriana .cdri5-82.acpc

Soraya Husain-Talero

Universidad de los Ande, Colombia

soraya.husain.talero@gmail.com

ORCID: http://orcid.org/0000-0002-7524-8786

DOI: https://doi.org/I0.III44/Javeriana.cdri5-82.acpc

Redalyc: http://www.redalyc.org/articulo.oa?id=11757724003

Recibido: 30 Marzo 2018 I Publicación: I8 Diciembre 2018

\section{Resumen:}

El artículo analiza los costos de producción y la cadena de valor de las plantas tradicionales que cultivan los campesinos de Cundinamarca, específicamente del municipio de Chipaque. Así, se evidencian los retos productivos a los que se enfrentan, dadas las tensiones entre la racionalidad economicista y una racionalidad alternativa en la cual se toman en cuenta las prácticas socioeconómicas junto con las diversas formas de valorar. Se resalta el carácter heterogéneo de los campesinos y el funcionamiento de la cadena de valor de las plantas tradicionales desde la parcela hasta las ventas en la plaza de mercado municipal, en la ciudad de Bogotá, y a partir del proceso de deshidratación.

Palabras clave: campesinos, Cundinamarca, costos de producción, plantas tradicionales, cadenas de valor. 


\title{
Analysis of the Production Costs and the Value Chain of Traditional Plants Grown by Peasants from Cundinamarca Province, Colombia
}

\begin{abstract}
:
This article analyses the production costs and the value chain for the traditional plants grown by the Cundinamarca peasants, specifically in the town Chipaque. This way, the work shows the production challenges faced by the peasants due to the tensions between the economism rationality and the alternative rationality. The latter considers the socioeconomic practices together with different forms of valuing the things. This work highlights the heterogenous nature of the peasants as well as the workings of the value chain in the traditional plants production, from the land to the selling place at the town markets in Bogotá, taking into account the dehydration process.
\end{abstract}

Keywords: peasants, Cundinamarca, production costs, traditional plants, value chains.

\section{Introducción}

El análisis de los costos de producción es un aspecto importante a considerar en un proyecto productivo, dado que permite fijar los precios de venta para generar ganancias, según la teoría económica neoclásica, a lo largo de la cadena de valor (Mankiw, 20I2). Sin embargo, esto representa una dificultad para la mayoría de campesinos, pues llevan contabilidades bajo racionalidades alternativas en las que utilizan una mano de obra de carácter familiar; cultivan una gran diversidad de productos, con diferentes tipos de insumos, tanto químicos como orgánicos; priorizan el cuidado de la naturaleza y el mejoramiento de las condiciones de vida, o porque simplemente su producción no se concibe dentro de una racionalidad economicista o no se encuentra subordinada al mercado capitalista (Akram-Lodhi, 2000). Asimismo, el excesivo poder de unos pocos actores que determinan oligopolios, junto con una excesiva intermediación y el poco nivel de negociación por parte de los campesinos, hace que estos se vean obligados a vender sus productos a precios bajos, incluso por debajo de los costos de producción. Esto, sin duda, genera inquietudes frente a su continuidad y permanencia como trabajadores del campo, debido a la cantidad y variedad de su producción y a sus niveles de satisfacción de necesidades (Acevedo-Osorio y Marti\#nezCollazos, 20I6). Por lo tanto, tal como lo proponen Mitchell, Keane y Coles (2009), las cadenas de valor permiten entender la interacción entre los actores, las relaciones de poder y el mercado a nivel local, junto con la red de alianzas horizontales y verticales que permiten transformar un producto, desde su producción hasta su consumo, y las estrategias adoptadas para distribuirlo y comercializarlo (Bu\#yu\#ko\#zkan, Feyzioglu y Nebol, 2008).

De esta manera, el artículo analiza las tensiones entre la racionalidad economicista, que mide los costos de producción como elemento importante de la estructura financiera y operativa y establece cadenas de valor, y la racionalidad alternativa, en la cual se toman en cuenta las prácticas socioproductivas que realizan los campesinos, resaltando sus características socioeconómicas y las relaciones de producción.

La investigación se sitúa en el municipio de Chipaque, Cundinamarca, ubicado en la cordillera oriental de los Andes colombianos, el cual es uno de los mayores productores de plantas medicinales, aromáticas y condimentarias del país (Municipio de Chipaque, 20I2). Las plantas que se producen en Chipaque han sido descritas como "plantas aromáticas, condimentarías y medicinales (PACM)” por el Ministerio de Agricultura y Desarrollo Rural, pero son consideradas como "plantas tradicionales" por los campesinos, pues hacen parte de la cultura popular. En consecuencia, en el presente trabajo se utiliza el término plantas tradicionales para hacer referencia a estas plantas. 
El artículo se estructura en tres partes. En la primera, se analizan los costos de producción reportados por los diferentes actores que participaron en la investigación. Así, se resalta el carácter heterogéneo de la población, a partir de las categorías planteadas por Forero (2002), relacionadas con la producción familiar de infrasubsistencia (las cuales ejemplifican las desigualdades existentes en el campo y los problemas asociados al modelo económico actual) y subsistencia y con las empresas agropecuarias de menor y mediana escala. En la segunda parte, se analiza el valor económico (precio) de las plantas tradicionales en los diferentes canales de distribución, incluyendo la venta directa en la parcela y en las plazas de mercado de Chipaque y la Samper Mendoza, en Bogotá, al detal y al por mayor. Y, en la tercera, se presenta un análisis sobre la importancia de generar valor agregado a partir de la transformación de las plantas, específicamente mediante la preparación de ungüentos y la deshidratación. No obstante, se describen las percepciones de los campesinos frente a estas prácticas y las razones por la cuales no todos están de acuerdo con estas.

Así, el artículo aporta una reflexión valiosa frente a la temática de costos y fijación de precios a las cadenas de valor, así como a los programas que apoyan al campesinado en la actualidad y a la idea de que todos los campesinos quieren/pueden convertirse en empresarios o en actores activos dentro del sistema capitalista; desafortunadamente, mientras no se comprenda la heterogeneidad del campesinado, será imposible modernizar el campo y mejorar la calidad de vida de sus habitantes. Además, se demuestra la necesidad existente de profundizar en la conceptualización, el análisis y las intervenciones que se realizan frente a las cadenas de valor, tanto desde el sector público como el privado, con el fin de lograr la participación de la población más vulnerable (Dietmar, Donovan, Fisk y Muldoon, 20I2). También se plantea que es fundamental que las entidades encargadas de la planeación y ejecución de políticas públicas en el sector rural conozcan estas dinámicas con el fin de desarrollar programas que propendan por la contribución a un desarrollo rural integral (Beltrán, 20ı6; Machado, 20r7; Marsden, Banks y Bristow, 2000).

\section{Metodología}

La presente investigación se realizó en el municipio de Chipaque, Cundinamarca, el cual se encuentra ubicado a $27 \mathrm{~km}$ de la ciudad de Bogotá, en la cordillera oriental de los Andes. Posee una extensión total de 1394,5 km² (la extensión del área urbana es de 2,I km², y de la rural, $1392,4 \mathrm{~km}^{2}$, es decir, el 99,85\%) y una temperatura media de $\mathrm{I} 3$ ${ }^{\circ} \mathrm{C}$, la cual es idónea para el cultivo de una gran variedad de plantas tradicionales (Municipio de Chipaque, 20ı2).

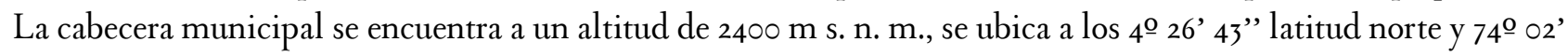
48 ' longitud oeste y está en un rango de altura que va desde los 1750 hasta los $3800 \mathrm{~m} \mathrm{s.} \mathrm{n.} \mathrm{m.} \mathrm{(Instituto} \mathrm{Geográfico}$ Agustín Codazzi [IGAC], 1999). Su ubicación se puede apreciar en la figura I. 


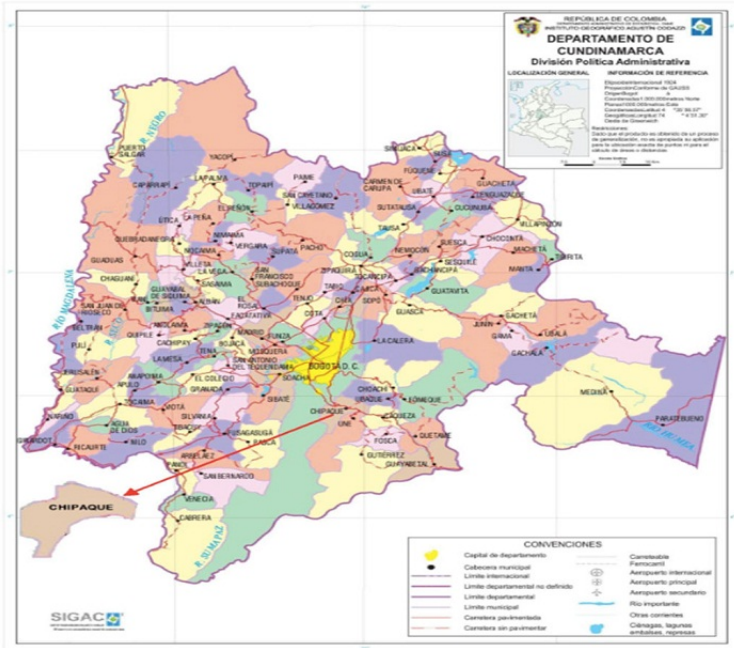

FIGURA 1

Ubicación de Chipaque en Cundinamarca

FuENTE: IGAC (1998)

La información que se presenta en el presente artículo surge de un trabajo de campo realizado entre 2015 y 2017 como parte de la tesis doctoral de la autora y fue realizado a partir de un enfoque cualitativo, con énfasis en una metodología etnográfica (Guber, 200I). Las técnicas de recolección de información incluyeron entrevistas abiertas y semiestructuradas a productores(as) y vendedores(as) campesinos(as) de Chipaque, junto con observación participante en las parcelas, en la plaza de mercado de Chipaque, en la Samper Mendoza, en Bogotá, y en supermercados de cadena ubicados en la ciudad de Bogotá. Así, con el fin de conocer la cotidianidad de los campesinos y sus prácticas socioeconómicas, se realizaron estancias prolongadas en el municipio, durante periodos que oscilaron entre 3 días a 2 semanas. En particular, se resaltan las vivencias y la información proporcionada por tres campesinos, los cuales aparecen en el artículo bajo los nombres de Nancy, Daniel y Ángel. Ellos accedieron a participar libremente en la investigación, pero sus nombres fueron modificados en aras de mantener su anonimidad. Además, se realizaron 25 entrevistas estructuradas relacionadas con el precio de las i4 plantas tradicionales más vendidas en Chipaque y se calculó el promedio (se escogió un volumen de 100 g como medida comparativa) con el fin de plantear generalizaciones. Estas entrevistas se realizaron con productores en las parcelas y con vendedores en la plaza de mercado de Chipaque y en la Samper Mendoza, en Bogotá. Lo anterior se consideró relevante dada la importancia de rastrear el precio a lo largo de la cadena de valor, obteniendo información de primera mano, frente a las negociaciones que se realizan al detal y al por mayor.

En términos teóricos, la investigación se enmarcó dentro de un enfoque sustantivista de la antropología económica, el cual busca demostrar que las decisiones económicas "están incrustadas y enredadas en instituciones económicas y no económicas” (Polanyi, I982, p. I6I), razón por la cual también se incluyen anécdotas sobre las prácticas y dinámicas sociales de los campesinos y vendedore

\section{Análisis de resultados}

\section{Costos de producción}

El análisis de costos de producción demostró que los campesinos de Chipaque siguen siendo una población heterogénea en términos socioproductivos, dado que se diferencian significativamente en cuanto a las relaciones de producción, al nivel de desarrollo de las fuerzas productivas y a su integración al mercado capitalista. Así, a 
continuación se describe el análisis de sus costos de producción utilizando tres categorías elaboradas por Forero (2002), las cuales son: I) campesinos con producción familiar de infrasubsistencia y subsistencia, 2) empresas agropecuarias de menor escala y 3 ) empresas agropecuarias de mediana escala.

En cuanto a la primera categoría, los campesinos con producciones familiares de infrasubsistencia tienen poca capacidad de negociación en el mercado y su nivel de tecnificación es casi nulo. Ellos hacen el intento de producir algunas plantas, pero las fuerzas productivas no los favorecen (terreno inadecuado, escasez de mano de obra, etc.), por lo que no logran obtener el mínimo para sobrevivir y, por lo tanto, no suelen llevar un análisis de costos de producción, puesto que su énfasis productivo se enfoca en la sobrevivencia personal y la de su familia, dadas las condiciones de pobreza en las cuales se encuentran (Forero, 1999; Machado, 1991).

Por su parte, los campesinos con producciones de subsistencia sí logran balancear la producción con el consumo, y la toma de decisiones se centra en sus experiencias y sus conocimientos (Forero, 2002). Aunque son conscientes de los costos, tampoco llevan un análisis detallado, puesto que la labor productiva se lleva a cabo de manera permanente y se acude a la autoexplotación, tal como lo plantean los estudios clásicos del campesinado (Wolf, 1966). Estos campesinos, incluso, producen sin saber a ciencia cierta el precio de venta de los productos o si van a recuperar el dinero invertido en la producción, puesto que el mercado de las plantas tradicionales es incierto y cambiante.

No obstante, productores como Nancy, quien es dueña de su parcela y fabrica su propio abono orgánico para sus plantas, no compran insumos externos en el mercado y por eso sus gastos son menores; además, siembran los brotes de las plantas antiguas para sacar plántulas nuevas y seguir mejorando su producción. Entre los costos de producción de Nancy se encuentran el transporte y la compra de algunas herramientas. Para ella, los precios de venta no se relacionan directamente con los costos de producción, sino con los valores que se asocian a las plantas tradicionales, por ejemplo, a su carácter natural y saludable, dada su naturaleza orgánica, y, en menor medida, a sistemas de contabilidad formales.

Con respecto a la segunda categoría, los campesinos que poseen producciones agropecuarias de menor escala presentan prácticas heterogéneas en términos de producción, puesto que aún mantienen prácticas agrícolas tradicionales, utilizan herramientas medianamente tecnificadas y realizan análisis de costos a mediano plazo. Gran parte de estas empresas son administradas por campesinos que han adoptado prácticas de producción parcialmente tecnificadas y que se encuentran integrados al mercado capitalista. Estos productores son conscientes de que "para sobrevivir en este mercado [el mercado de las plantas tradicionales dentro del capitalismo], uno tiene que ser muy cuidadoso con sus inversiones", como afirma Daniel, un productor que utiliza terminología económica para hablar sobre sus costos de producción.

Él realiza una estimación de costos básica en la cual integra el precio de los insumos que compra (especialmente abonos, agroquímicos y semillas) y las actividades que realiza. Así, menciona lo siguiente: "Invertí \$ 1.000.000 este mes en el cultivo de yerbabuena y caléndula y espero sacar $\$ 3.000 .000$ cuando los empiece a vender en 3 meses". Daniel calcula los costos fijos de producción de manera sistemática y estima su ganancia con base en un tiempo determinado, teniendo en cuenta que trabaja todos los días en su parcela. Añade que no se centra en un punto de equilibrio, como sí lo hacen otros campesinos, sino que su objetivo es generar utilidades porque tiene una hija y un nieto que debe mantener. Él "lleva toda la contabilidad en [su] cabeza”, pero aclara que sí guarda las facturas importantes, no porque se le vaya a olvidar cuánto pagó, sino en caso de que le toque luchar por alguna garantía.

Ángel, otro campesino de la región, sí lleva tablas de contabilidad e incluye costos programados, como la mano de obra, el costo de la tierra, los insumos, las herramientas y los imprevistos, puesto que "siempre se puede presentar algo, principalmente por el clima, y si uno no tiene el dinero para cubrir los imprevistos, puede perder la cosecha por completo", afirma. Los imprevistos incluyen máquinas o herramientas que se dañan y costos de transporte y de almacenamiento inesperados. 
Algunos de los costos de producción de caléndula reportados por Ángel se encuentran en la tabla i. Entre los costos más altos, se encuentran el alquiler de la tierra y la compra de insumos, seguidos por el transporte, la mano de obra y los imprevistos. Ángel hace cálculos sobre la tierra, a pesar de que él es el propietario, y sobre los altos costos de los insumos, incluyendo agroquímicos, fertilizantes y abonos. Las plantas de caléndula, por ejemplo, se deben abonar cada 15 días, durante la floración, y se deben fumigar cada 20 días para erradicar las plagas; por eso, él reporta que gasta más o menos $\$ 800.000$ en ese rubro.

TABLA 1

Costos de PRODUCCIÓN DE CALÉNDULA

\begin{tabular}{llccc}
\hline Rubro & Unidad & Cantidad & $\begin{array}{c}\text { Costo unitario } \\
\text { (en pesos } \\
\text { colombianos) }\end{array}$ & $\begin{array}{c}\text { Costo total } \\
\text { (en pesos } \\
\text { colombianos } \\
\text { ) }\end{array}$ \\
\hline Preparación del suelo & Hectárea & 1 & & 200.000 \\
\hline Alquiler de la tierra & Hectárea & 8 & & 1.200 .000 \\
\hline Siembra & Jornal & 5 & 20.000 & 100.000 \\
\hline Insumos & Global & 1 & 800.000 & 800.000 \\
\hline Cosecha & Jornal & 10 & 20.000 & 200.000 \\
\hline Herramientas & Global & 1 & 200.000 & 200.000 \\
\hline Análisis de suelo & Global & 1 & 80.000 & 80.000 \\
\hline Transporte & Global & 4 & 92.000 & 368.000 \\
\hline Imprevistos & & & & 286.000 \\
\hline Total & & & & \\
\hline & & & & \\
\hline & & & & \\
\hline
\end{tabular}

Fuente: elaboración propia

Nota: Cabe anotar que los datos anteriores pueden contener algunos errores, ya que, como mencionan Fajardo et al. (198I), el campesino no contabiliza en el precio final de sus productos el costo de su mano de obra ni el de la de su familia y tampoco lleva un control estricto de las inversiones realizadas, como es el caso de Ángel. Por esta razón, se cree que, en la práctica, los costos de producción mencionados pueden ser mucho más altos que los relacionados.

Además, la sobreutilización y el ineficiente uso de agroquímicos, junto con la falta de capacitación, incrementa los costos de producción, puesto que a veces se fumiga de manera innecesaria. Esta temática ha sido resaltada en diversos informes de la Organización de las Naciones Unidas para la Alimentación y la Agricultura (FAO) (2015), en los que, incluso, se indica que afecta de manera directa el bienestar económico y social de los campesinos. Ángel confiesa que en ocasiones ha tenido que

improvisar y proteger el cultivo sin importar lo que pase. Hay veces llueve mucho o hay mucha sequía y sol, o llegan muchas plagas, y a uno le toca tomar cartas en el asunto y salvar la inversión cueste lo que cueste... por eso la ganancia no siempre es tan buena. 
No obstante, antes de cultivar, Ángel acostumbra a realizar estudios de análisis de suelo, los cuales tienen un costo de \$80.000 cada uno; esta es una buena estrategia, ya que por medio de dichos análisis se logra saber la concentración de los nutrientes del suelo con el fin de fortalecerlos bajo un uso justificado de insumos.

En relación con la tercera categoría, las empresas agropecuarias de mediana escala que se encuentran en Chipaque han adoptado sistemas agrícolas tecnificados con el fin de obtener una mayor productividad. Estas empresas poseen un mayor nivel de integración al mercado, cuentan con mano de obra fija y tienen procesos tecnificados, siguiendo los parámetros impuestos por el mercado capitalista, ya que generan productos completamente homogéneos, utilizan una buena variedad de agroquímicos e insumos y llevan un análisis de costos de producción de manera detallada, con el fin de invertir eficientemente los recursos, teniendo en cuenta las lógicas de la economía agroindustrial. Sin embargo, ninguna empresa accedió a compartir datos sobre sus costos de producción con la investigadora, pues hay una gran desconfianza en el subsector productivo. Al preguntarle a una persona sobre este tipo de información, ella respondió lo siguiente: "Eso es bien complicado; yo tengo todo al día, pero esa información completa no se la doy ni a la DIAN [Dirección de Impuestos y Aduanas Nacionales] ... yo le digo que esto es un buen negocio, pero no puedo darle ningún detalle”. Estas empresas, por lo general, son administradas por personas que provienen de otros lugares y que han estudiado el negocio de la producción de plantas tradicionales, particularmente en términos económicos. Estas se centran en una racionalidad económica y en obtener la mayor productividad y ganancia posible.

\section{Precio promedio de las plantas en los diferentes canales de distribución}

Con relación al precio promedio otorgado a las plantas en los diferentes canales de distribución, se encontró que este varía sustancialmente dependiendo de la cantidad de la planta (si es al mayor o al detal), del lugar donde se realiza la transacción (parcela, plaza de mercado de Chipaque, plaza de mercado de Bogotá o supermercado de cadena), del actor que realiza la venta (campesino productor, intermediario o vendedor) y del valor agregado que se le incluye al producto (por ejemplo, cuando se deshidrata). En este sentido, se considera como precio la suma de dinero que el consumidor o comprador cambia por poseer o acceder a un producto o servicio (mercancía) (Mankiw, 2012; Mejía, 2005).

Según la economía neoclásica, el proceso de fijación de precios está sujeto a la oferta y la demanda, el grado de posicionamiento del producto, la competencia, los costos de producción y operación, los canales de distribución y la finalidad o el uso que tiene el producto (Bernal, 2007; Mejía, 2005). No obstante, dentro de la economía campesina, la fijación de precios sigue una lógica parcialmente distinta, puesto que se destacan el trabajo y el esfuerzo invertido para cultivar el producto; la valoración que le atribuye el productor a las plantas en términos de su valor terapéutico, simbólico, mágico-religioso, entre otros; la necesidad que tiene el comprador de adquirir la planta; los lazos de amistad entre el productor y el comprador; la información que se tiene sobre la demanda; las tendencias de cada planta en el mercado, y los costos de producción. Por ende, se evidencia que la lógica de fijación de precios entre los diferentes actores que se encuentran presentes en la cadena de valor de las plantas tradicionales varía sustancialmente.

En la figura 2 se muestran las variaciones de precio de las i4 plantas tradicionales, las cuales fueron escogidas por ser las más vendidas en Chipaque. En el gráfico se utilizó una escala logarítmica, con el fin de incluir todos los precios de las plantas, dado que estos cubren un amplio rango y el logaritmo permite graficarlos de manera organizada. 


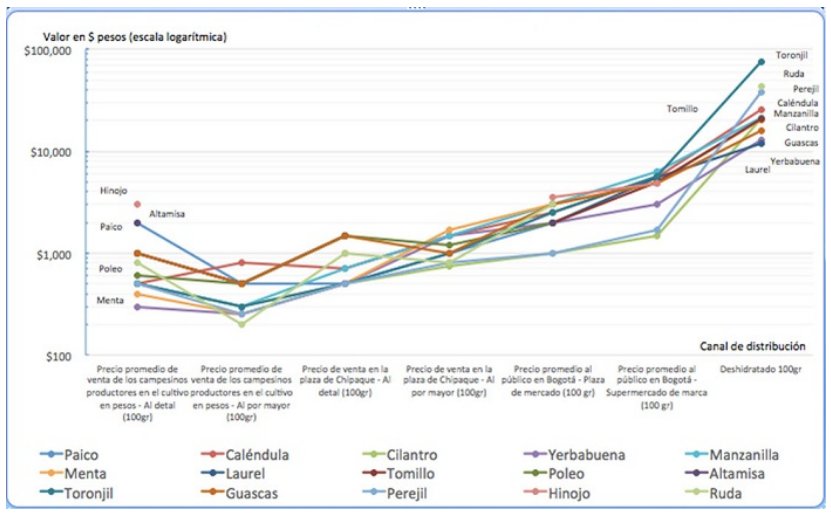

FIGURA 2

Precio PRomedio de las plantas tradicionales EN los DifERENTES CANALES DE DisTRibució

FUENTE: ELABORACIÓN PROPIA

Se puede observar que la tendencia es que el precio promedio de venta de las plantas tradicionales al detal en el cultivo es relativamente alto y que luego este se reduce cuando se venden al por mayor. La única excepción es la caléndula, la cual incrementa su precio en el cultivo al por mayor en comparación con la venta al detal. Luego, a medida que las plantas transitan por los diferentes lugares y procesos de distribución (plaza de mercado de Chipaque, plaza de mercado Samper Mendoza, supermercado en Bogotá y proceso de deshidratado), su precio sube sustancialmente. Asimismo, se evidencia que el precio de venta de las plantas en la plaza de Chipaque, cuando estas se llevan a la plaza Samper Mendoza, se incrementa por el costo de transporte del producto. Luego, cuando las plantas llegan a los supermercados en Bogotá, estas se limpian y se empacan y se venden a un mayor precio. Asimismo, cuando las plantas son sometidas a un proceso de deshidratación, su precio se multiplica exponencialmente.

\section{Discusión}

\section{Costos de producción reportados por los diferentes}

\section{actores}

Se evidencia que los campesinos con producciones de infrasubsistencia no llevan un análisis de costos de producción puesto que su labor se centra en la supervivencia y se sustenta en mayor grado en la economía moral y en la solidaridad que está presente en la comunidad. Por su parte, los campesinos con producciones de subsistencia mencionan que su propuesta productiva es rentable siempre y cuando el uso de insumos externos sea mínimo. Este es el caso de Nancy, por ejemplo, quien se considera pionera con su modelo productivo y quien hoy en día tiene una vida relativamente cómoda, con todas sus necesidades básicas satisfechas; ella demuestra que, a pesar de que la situación de los habitantes del campo es difícil, existen formas de resistencia que han influido en su reproducción como grupo social. Al respecto, indica lo siguiente: "Lo que se vive hoy en día no es nada raro. Mis abuelos también tuvieron que luchar, y los abuelos de ellos también. Es cuestión se verraquera, inteligencia y saber actuar con base en unos valores firmes". Para ella, el actuar campesino está directamente relacionado con los valores y la moralidad que le inculcan la comunidad y la familia a cada uno de sus miembros, y, de esta manera, hace énfasis en la obligación que ellos tienen de mantener su soberanía alimentaria, la calidad de los alimentos y los recursos naturales con el fin de heredárselos a las futuras generaciones (Ploeg, 2010; Vélez, 2015). Esta visión demuestra la vigencia de una economía moral (Scott, 1976; Thompson, I97I), puesto que hay principios inamovibles que, a pesar de los años y las 
diferentes fuerzas internas y externas, siguen guiando el ser y el deber-ser de los campesinos, lo que demuestra la actualidad de racionalidades alternativas al modelo capitalista. Esto no significa que Nancy no busque ganancias económicas, pero ese no es su objetivo principal, contrario a lo que sucede bajo la lógica economicista del modelo capitalista (Landini, 20II). Ella es consciente de la mercantilización de la economía campesina y de la importancia del dinero para obtener servicios y los productos que no puede cultivar.

Además, la diversificación de cultivos en forma de policultivos permite disminuir los riesgos asociados a la producción, pues permite controlar las plagas y demás enfermedades que pueden afectar a las plantas, junto con la incertidumbre asociada a la venta (Chonchol, 1990; Ellis, 2000; Landini, 20II). Asimismo, dada la necesidad que tienen los campesinos de infrasubsistencia y de subsistencia de sobrevivir a corto plazo, junto con las condiciones en las cuales se desarrolla su producción (en relación con el bajo acceso a créditos, herramientas, asistencia técnica y capacidad de negociación en el mercado), es incoherente proponerles un tipo de producción en el cual los beneficios económicos se generen a mediano y largo plazo, tal como lo proponen los proyectos de desarrollo rural actuales. Los campesinos perciben que hay situaciones que están fuera de su control y, por esta razón, tal como lo indica Seligman (1989), no calculan un bienestar económico a largo plazo; en caso de necesitar ayuda en un futuro, la mayoría de campesinos acudirían a sus amigos y vecinos apelando a la economía moral o acudirían a la pluriactividad.

En relación con los campesinos con producciones de menor escala, los costos de producción siguen siendo muy inciertos, puesto que manifiestan estar expuestos a un sinnúmero de situaciones que no siempre pueden controlar o manejar de manera adecuada, junto con la falta de subsidios por parte del Gobierno. Como menciona Mayer (1999), el subsidio al productor genera utilidades y empleo que se convierten en aumentos en la demanda de productos, y esto tiene efectos multiplicadores en las comunidades campesinas. A pesar de que en Colombia se han intentado impulsar algunos subsidios, como en el caso de los incentivos a la capitalización rural (ICR), los campesinos de Chipaque no han sido beneficiarios, dada su cercanía con Bogotá y por la naturaleza de sus productos, los cuales no son considerados como productos vanguardia en los planes de subsidio, en comparación con el arroz, el café o las frutas. Esta situación se puede generalizar con otros campesinos de Chipaque y en otras zonas del país, como lo resaltan Kalmanovitz y López (2006).

Asimismo, los campesinos con producciones de menor escala mencionan que existen dificultades frente a la obtención de créditos, por lo que acuden a los préstamos que realizan los establecimientos que venden insumos, a pesar de tener tasas de interés exageradas. Según ellos, los establecimientos impulsan la venta de los agroquímicos más costosos y realizan créditos únicamente sobre estos, los cuales no siempre son los mejores. Esto contribuye a la incertidumbre productiva del campesino y a su marginalidad, ya que por más que ellos quieran tener una producción continua y participar activamente en el mercado capitalista, los altos costos de producción y las dinámicas frente a la estandarización generan dificultades. Esto se debe a que la estandarización de los procesos de producción asume que todos los campesinos que están participando en estos procesos tienen las mismas capacidades y cuentan con recursos similares, ignorando su heterogeneidad en términos económicos y sociales y dejando de lado la intuición y la experiencia de la vida rural. Para estos campesinos, el conocimiento vivencial es fundamental y no es lógico plantear manuales estandarizados, porque se estarían ignorando el conocimiento y la experiencia acumulados a lo largo de generaciones.

Además, la estandarización sin una adecuada preparación puede conducir a mayores costos e incrementar la vulnerabilidad del campesino, pues, como menciona Vélez (2015), reduce la flexibilidad productiva y la autonomía en la toma de decisiones sobre el manejo de los cultivos, lo que afecta de manera directa el sustento de los campesinos. Igualmente, como lo demostraron investigaciones realizadas por Jaffee y Henson (2005) y Shiva (2013), entre otros, estas dinámicas homogeneizantes también afectan la calidad de los productos, la soberanía y el entorno ambiental. De igual manera, la estandarización es un dispositivo que fortalece solamente una visión de mundo, proporcionada por los profesionales que validan ese "estándar” particular (Escobar, 2007) 


\section{El valor económico de las plantas tradicionales en los diferentes lugares de distribución Comparación de precios de venta en la parcela}

Durante el trabajo de campo, se encontró que el proceso de fijación de precios es diverso, pues no solo se relaciona con costos de producción, sino que incluye cálculos subjetivos que realiza el campesino vendedor sobre el comprador, los beneficios que la planta va a generar en aquel que la utilice y la amistad que el comprador tiene con el campesino vendedor. En la tabla 2 se pueden apreciar los precios promedio de venta en las parcelas.

TABLA 2

Precio de venta de las plantas tradicionales en las parcelas

\begin{tabular}{lcc}
\hline \multirow{2}{*}{ Planta } & $\begin{array}{c}\text { Precio promedio de venta de las plantas tradicionales } \\
\text { en el cultivo (en pesos colombianos) }\end{array}$ \\
\cline { 2 - 3 } & Al detal $(100 \mathrm{~g})$ & Al por mayor $(100 \mathrm{~g})$ \\
\hline Paico & 2000 & 500 \\
\hline Caléndula & 500 & 800 \\
\hline Cilantro & 500 & 300 \\
\hline Yerbabuena & 300 & 250 \\
\hline Manzanilla & 500 & 300 \\
\hline Menta & 400 & 250 \\
\hline Laurel & 1000 & 500 \\
\hline Tomillo & 1000 & 500 \\
\hline Poleo & 600 & 500 \\
\hline Altamisa & 2000 & No se encontró \\
\hline Toronjil & 500 & 300 \\
\hline Guascas & 1000 & 500 \\
\hline Perejil & 500 & 250 \\
\hline Ruda & 800 & 200 \\
\hline
\end{tabular}


Se encontró que los campesinos obtienen una mayor ganancia cuando venden las plantas tradicionales en su parcela y al detal, ya que el precio promedio es relativamente más alto, sobre todo en el caso del paico y la ruda. La ganancia con las guascas, el perejil, el laurel y el tomillo es del 50\%, seguido por el $40 \%$ de ganancia con el cilantro, la manzanilla y el toronjil. La ganancia es menor con la menta, con un $37,5 \%$, pero este puede ser relevante para un campesino que se encuentra en condición de infrasubsistencia. Por lo general, las ventas que se realizan al detal son hechas a campesinos de la zona que necesitan la planta de manera urgente para realizar algún tipo de práctica terapéutica, simbólica, ecológica, alimenticia o mágico-religiosa. En estos casos, el campesino productor arranca unos gajos y los vende, con lo que genera, de esta manera, una ganancia económica considerable en comparación con la venta al por mayor, y el campesino que compra u obtiene la planta sabe que va a consumir o utilizar una planta fresca, recién cortada, que tiene todas las propiedades necesarias para equilibrar el cuerpo, el espíritu y el ambiente que lo rodea.

Así, resulta más rentable para el campesino vender las plantas directamente en la parcela, pues existe mayor poder de negociación, se pueden fijar el precio, según la cantidad de trabajo invertido, el nivel de escasez e incluso sus propiedades y el campesino no está sujeto a las leyes del mercado o a lo que decidan los intermediarios; a su vez, los compradores campesinos por lo general prefieren esta modalidad de compra, puesto que ellos mismos pueden escoger la planta, cortarla y, así, asegurarse de su procedencia. Por ejemplo, la altamisa y el paico son muy buscadas en la comunidad por campesinos que las necesitan lo más frescas posible para realizar limpiezas: el paico sirve para purgar el cuerpo y la altamisa sirve para purgar el espíritu.

Las plantas que se venden al por mayor en la parcela por lo general tienen una disminución en el precio, lo cual se considera como un fenómeno normal, ya que a mayor cantidad, menor es el precio unitario de la mercancía. Entre las plantas que sufren esta caída en el precio se encuentran el paico, el laurel, el tomillo, las guascas y la ruda. La única planta que se vende mejor al por mayor que al detal es la caléndula, pues su precio se incrementa en un $60 \%$. Dadas la gran demanda de caléndula en el mercado -por parte tanto de los consumidores como de los laboratorios que producen cosméticos y cremas para la piel- y la escasez de oferta en ciertas temporadas, los compradores están dispuestos a pagar un precio más alto con tal de encontrar la cantidad que necesitan, y los campesinos, que conocen esta información, la venden a un precio más alto.

Así, hoy en día, el cultivo más rentable para vender al por mayor en la parcela es la caléndula, siempre y cuando los gastos de transporte sean asumidos por el comprador. No obstante, solo los productores con extensas parcelas y con una producción continua se benefician de este tipo de venta.

\section{Comparación de precios de venta en la plaza de mercado de Chipaque}

La venta al detal en la plaza de mercado de Chipaque también es beneficiosa para los campesinos, puesto que obtienen un mejor precio en comparación con la venta en la parcela. Por ejemplo, el precio de la caléndula, la manzanilla y la yerbabuena al detal sube en promedio un $40 \%$ del cultivo a la plaza, mientras que el precio del laurel, el tomillo y las guascas se incrementa un 50\%. Todas estas plantas tienen una gran rotación dado que son bastante conocidas y tienen un alto valor de uso; se pueden utilizar en diferentes contextos, desde un ámbito condimentariogastronómico, como en el caso del laurel, el tomillo, las guascas y la yerbabuena, hasta un ámbito terapéutico, para tratar aflicciones pulmonares y en la piel, como en el caso de la caléndula y la manzanilla. El precio de la planta tradicional que más se incrementa en este tránsito es el del poleo, que lo hace en un $150 \%$, pues es una planta que tiene una gran demanda en el municipio al ser utilizada para hacer las rellenas o morcillas, que son un plato 
típico del municipio. Así, el incremento del precio descrito se da principalmente por el transporte de los productos - de la parcela a la plaza-y por el esfuerzo que deben hacer los campesinos.

En la tabla 3 se pueden apreciar los precios de venta promedio en la plaza de mercado al detal y al por mayor; el precio al por mayor es más alto que el precio al detal para la mayoría de las plantas mencionadas, excluyendo el poleo y las guascas, las cuales se venden mejor al detal. Esto demuestra que el mercado capitalista recompensa la cantidad, la productividad y la eficiencia y que los campesinos que no han logrado entrar en esta dinámica productivista no obtienen ganancias. Es por esto que algunos campesinos han optado por asociarse entre ellos y delegar a un líder campesino para que venda sus productos, para luego dividir las ganancias según la cantidad aportada. No obstante, es importante considerar que el campesino que sí produce grandes cantidades de plantas tradicionales también tiene mayores costos de producción, y, por esta razón, mayor cantidad de producto no siempre significa mayor ganancia económica.

TABLA 3

Precio de venta de las plantas tradicionales en la plaza de mercado de Chipaque y en Bogotá

\begin{tabular}{|c|c|c|c|c|}
\hline \multirow{2}{*}{ Planta } & \multicolumn{2}{|c|}{$\begin{array}{c}\text { Precio promedio de venta de las } \\
\text { plantas tradicionales en la plaza } \\
\text { de mercado de Chipaque (en } \\
\text { pesos colombianos) }\end{array}$} & \multicolumn{2}{|c|}{$\begin{array}{l}\text { Precio promedio de venta de las } \\
\text { plantas tradicionales en Bogotá (en } \\
\text { pesos colombianos) }\end{array}$} \\
\hline & $\mathrm{Al}$ detal $(100 \mathrm{~g})$ & $\begin{array}{l}\text { Al por mayor } \\
(100 \mathrm{~g})\end{array}$ & $\begin{array}{l}\text { Plaza de mercado } \\
\text { Samper Mendoza } \\
\text { (100 g) }\end{array}$ & $\begin{array}{l}\text { Supermercado de } \\
\text { cadena }(100 \mathrm{~g})\end{array}$ \\
\hline Paico & 500 & 1000 & 2000 & No se encontró \\
\hline Caléndula & 700 & 1500 & 2500 & 5500 \\
\hline Cilantro & 500 & 750 & 1000 & 1500 \\
\hline Yerbabuena & 500 & 1500 & 2000 & 3000 \\
\hline Manzanilla & 700 & 1500 & 3000 & 6300 \\
\hline Menta & 500 & 1700 & 3000 & 5000 \\
\hline Laurel & 1500 & No se encontró & 2000 & 5500 \\
\hline Tomillo & 1500 & No se encontró & 2000 & 5000 \\
\hline Poleo & 1500 & 1200 & 2000 & No se encontró \\
\hline Altamisa & 1500 & No se encontró & 2000 & No se encontró \\
\hline Toronjil & 500 & 1000 & 2500 & 5700 \\
\hline Guascas & 1500 & 1000 & 3000 & 4900 \\
\hline Perejil & 500 & 800 & 1000 & 1700 \\
\hline Ruda & 1000 & 800 & 3000 & No se encontró \\
\hline
\end{tabular}

Fuente: elaboración propia

Además, hay algunas plantas que, al detal, no cambian su precio de venta del cultivo a la plaza, como el cilantro, el toronjil y el perejil. En este caso, por lo general, el campesino asume los costos del transporte para venderlas, ya que estas plantas no tienen mucha demanda en el cultivo, y, dado que son productos perecederos, los campesinos 
deben tomar decisiones estratégicas sobre el mejor momento para venderlas, antes de que empiecen a marchitarse, pues su precio cae drásticamente. Otras veces, cuando no logran venderlas, las familias campesinas optan por consumirlas.

El paico es un caso muy particular porque el precio de la parcela a la plaza se devalúa en un $75 \%$ (de $\$ 2000$ al detal en la parcela a $\$ 500$ al detal en la plaza). Esto se debe a que es una planta altamente valorada por los chipaquences, pues la utilizan para purgar a jóvenes y niños, y por esta razón la mayoría de campesinos la cultivan o se la compran a los vecinos más cercanos y no hay necesidad de acudir a la plaza de mercado para conseguirla.

En épocas de cosecha, cuando las condiciones de producción son estables, los precios en la plaza de mercado pueden ser menores que los de la parcela, puesto que todos los campesinos llevan sus productos y, de esta manera, se genera una sobreoferta, situación que aprovechan los intermediarios. Además, dada la urgencia que tienen los productores campesinos de vender, ellos conscientemente reducen los precios con el fin de vender rápido. Esto sigue las lógicas del libre mercado, en las que la competencia funciona como mecanismo de regulación de precios y hace que estos disminuyan al límite más bajo posible (Mankiw, 20I2. Dado que los campesinos no pueden regresar a sus parcelas con plantas que no han vendido, porque estas se empiezan a marchitar, se ven obligados a vender su producción el mismo día del corte, sin importar el precio de venta.

Cuando se compara la venta al por mayor en la plaza por parte de los intermediarios con la venta al por mayor en la parcela, se evidencia que el incremento de precio es extremadamente alto, y la plusvalía la obtienen los intermediarios. Por ejemplo, el precio de la menta en promedio aumenta un $580 \%$; el de la yerbabuena, un $500 \%$; el de la manzanilla, un $400 \%$; el de la ruda, un $300 \%$; el del toronjil, un $233 \%$; el del perejil, un $220 \%$; el del cilantro, un $150 \%$; el del poleo, un $140 \%$; el de las guascas y el paico, un $100 \%$, y la que menos incrementa su precio es la caléndula, que lo hace un $87,5 \%$. De esta manera, se puede apreciar que los intermediarios son los que obtienen mayor ganancia, a pesar de no generar ningún valor agregado a las plantas.

\section{Comparación de precios de venta en Bogotá}

Dado que la mayoría de plantas tradicionales que se producen en Chipaque están dirigidas a los mercados de la ciudad de Bogotá, también se realizó un seguimiento de precios en dos lugares importantes: I la plaza de mercado Samper Mendoza, la cual es reconocida por la venta de plantas medicinales y mágico-religiosas provenientes de todo Colombia, y 2 diferentes supermercados de cadena ubicados en la zona norte de la ciudad. Los resultados se pueden apreciar en la tabla 3 .

Cuando las plantas tradicionales llegan a Bogotá, su precio se incrementa significativamente, y esto se debe principalmente al transporte y al papel de los intermediarios. Por ejemplo, el precio de la ruda se incrementa en promedio un 73\%; el del toronjil sube un 60\%; el del paico y la manzanilla, un 50\%; el de la caléndula y el poleo, un $40 \%$; el del cilantro y la yerbabuena, un $25 \%$, y el del perejil, un $20 \%$. Claramente, en la ciudad hay una mayor demanda de estas plantas, teniendo en cuenta la cantidad de población, la oferta reducida y la facilidad de acceso a la información sobre sus propiedades y usos.

También se evidenció que el precio en el supermercado de cadena es mucho mayor que en la plaza de mercado Samper Mendoza, sobre todo en el caso del laurel y el tomillo, los cuales se utilizan para condimentar diversas comidas de la gastronomía colombiana. Sin embargo, algunas plantas más tradicionales, como el paico, el poleo, la altamisa y la ruda, no se encontraron en el supermercado estudiado.

Como indica Harvey (1990), es a partir de estos análisis que se logra demostrar parte de los secretos del capitalismo y, así, evidenciar que el sistema de precios no es un mecanismo completamente descentralizado o imparcial, sino que se sustenta en una relación entre el valor de cambio, el valor de uso y otras valoraciones 
situacionales, teniendo en cuenta las diferentes dinámicas socioeconómicas que se encuentran presentes en todo tipo de transacciones.

\section{La importancia de generar valor agregado en las plantas tradicionales}

El valor agregado es una característica adicional que se le da al producto con el fin de darle mayor valor comercial (Abel y Bernanke, 2004). Esto puede incluir un mejor empaque o la trasformación del producto a otra presentación; por ejemplo, en nuestro caso, están la deshidratación o la fabricación de productos de belleza (champú, cremas corporales, etc.), lo cual permite vender el producto a un mejor precio (Kaplinsky y Morris, 2000).

Por esta razón, en Chipaque se han consolidado algunas microempresas, como, por ejemplo, Caléndula Organik's, la cual, a partir de las propiedades de la caléndula, ha desarrollado diversos productos, incluyendo crema dental, labial, aceite esencial y jabones. Esta empresa cuenta con registros Invima (Instituto Nacional de Vigilancia de Medicamentos y Alimentos), pero los productos no se comercializan en Chipaque, sino en diferentes puntos de Bogotá.

Asimismo, el valor agregado se puede generar a partir de la deshidratación, en la que se extrae gran parte de la humedad y se trata de conservar características como el color, el sabor y los componentes activos (Red de Agroindustria Rural [Redar], 199I). Este es un proceso sencillo, pero demorado, y, en cuanto al precio, parece ser muy ventajoso. Esta situación se señala en la figura 2, donde se muestra el precio promedio de las plantas cuando estas han sido deshidratadas.

Por ejemplo, el precio de la caléndula deshidratada por 100 g puede aumentar hasta 51,6 veces más que el del producto fresco; el de la ruda, 54,5 veces; el de la yerbabuena, 43,3 veces; el de la manzanilla, 42 veces, y el del perejil deshidratado, 76,5 veces. El producto deshidratado más costoso en promedio es el toronjil, cuyo precio es 151,2 veces más alto que el precio en fresco, por lo que genera una ganancia extraordinaria y demuestra que, aunque el proceso de deshidratación puede ser demorado y costoso, el precio de venta es favorable no solo en términos económicos para el campesino, sino también en lo referente a la vida útil del producto, lo que a su vez facilita los procesos de exportación.

De esta manera, se evidencia que la generación de valores agregados permitiría una mejor venta para los campesinos. Pero esta estrategia implica una inversión inicial alta y una mirada diferente a la actividad productiva. Por ejemplo, tal como lo indica Nancy: "No quiero deshidratar mis plantas porque, cuando uno hace eso, la planta pierde sus componentes activos. Eso es un maltrato a la naturaleza”. Ella señala que el carácter de su producción es tradicional y que el proceso de deshidratación con maquinaria contaminaría las plantas, puesto que se empezarían a utilizar tecnologías que afectan sus propiedades.

Campesinos como Ángel sí ven la necesidad de generar valores agregados en la producción, ya sea por medio de la deshidratación de las plantas para obtener un mejor precio o de la elaboración de pomadas o lociones. Él dice que espera que sus hijos crezcan para empezar a desarrollar alguna estrategia, sobre todo porque la demanda internacional de plantas tradicionales deshidratadas se ha incrementado, por lo que se han abierto nuevas posibilidades de comercialización.

Solo los campesinos que se encuentran "preparados" en términos socioeconómicos y tecnológicos y que cuentan con la información adecuada pueden pensar en desarrollar estrategias para generar valor agregado. El mayor reto es que los campesinos en condiciones de subsistencia e infrasubsistencia logren incursionar en estos mercados de manera efectiva y que logren sostenerse a largo plazo, cumpliendo con todas las exigencias del mercado capitalista 
y manteniendo a la vez su autonomía, sus tradiciones y su seguridad alimentaria. A su vez, es importante tener en cuenta que algunos campesinos no están interesados en generar valores agregados, pues se encuentran relativamente bien y saben que sus productos son comercializables por su carácter tradicional con compradores que así los valoran

\section{Conclusiones}

El artículo permite comprender la manera en la cual campesinos productores de plantas tradicionales ubicados en la cordillera oriental de los Andes analizan sus costos de producción y realizan el proceso de fijación de precios, junto con la manera en la cual los precios de sus productos se transforman a lo largo de la cadena de valor. Se evidencia, tal como lo indican los estudios clásicos del campesinado (Chayanov, 198ı, que en la economía campesina, como en el caso de los campesinos en condición de infrasubsistencia y subsistencia, no se pueden determinar objetivamente los costos de producción. El precio final del producto se decide según las circunstancias asociadas a la cantidad, su transporte, la relación existente entre compradores y vendedores, la valoración subjetiva que se les otorga a las plantas en términos sociales y simbólicos y el lugar socioespacial donde se realiza la transacción, entre otras. Por sus parte, los campesinos que se encuentran medianamente integrados al mercado capitalista, como en el caso de los campesinos con empresas agropecuarias de menor escala, sí realizan un análisis de costos y su producción se encuentra atravesada por las diversas tensiones que se presentan frente al uso de insumos externos, como es el caso de los agroquímicos que afectan la naturaleza y la estandarización de las prácticas productivas, los cuales, según mencionaron los entrevistados, afectan su autonomía. En este sentido, si bien las cadenas de distribución han permitido acercar ciertos productos a una gran diversidad de compradores, se sigue encontrando una gran cantidad de problemáticas asociadas a la falta de tecnificación, la desigualdad en términos de negociación, la falta de coordinación vertical y la poca capacidad de gerencia de los campesinos dentro de la racionalidad economicista (Swinnen y Maertens, 2007. Además, no es pertinente hablar de un solo tipo de campesino, sino de diversos, dadas sus prácticas productivas, su organización social y sus expectativas futuras (Acevedo-Osorio y Martínez-Collazos, 2016); por lo tanto, las políticas de desarrollo rural no solo deben concebirse dentro de un enfoque territorial, sino a partir de un enfoque de derechos, considerando las particularidades de la población (Tobasura, 20II).

En relación con la transformación del precio a lo largo de la cadena de valor, se evidencia que los campesinos obtienen una mayor ganancia cuando venden el producto en su parcela; una vez que este se transporta a la plaza, la ganancia de los campesinos disminuye y actores como los intermediarios empiezan a obtener mayor ganancia. Se demuestra, entonces, que la definición de cadena de valor como aquella interrelación basada en la confianza en la cual todos los actores se ven beneficiados no es apropiada (Webber y Labaste, 2010). Las políticas actuales son inadecuadas dado que no contribuyen al bienestar del campesino en términos de comercialización y valorización de sus productos; asimismo, la falta de subsidios hace que el sustento de los campesinos se vea vulnerado por la fluctuación y las exigencias que genera en el mercado capitalista, y esto genera inquietudes frente a la sostenibilidad económica de los campesinos productores a mediano plazo (Mitchell et al., 2009). Una estrategia para empezar a solucionar esta problemática es planteada por autores como Collantes (2018), quien explica la importancia de reducir la longitud de la cadena de valor y, de esta manera, asegurar que tanto el productor como el comprador obtengan el mejor precio y calidad del producto. Asimismo, Berdegué, Carriazo, Jara, Modrego y Soloaga (2015) y Dubbeling et al. (2017) resaltan la importancia de acortar las cadenas de valor en contextos en los que lo urbano y lo rural se encuentran cerca, como en el caso del municipio de Chipaque con Bogotá, con el fin de generar cadenas más sostenibles. 
Igualmente, la generación de valor se plantea como una alternativa costosa que requiere de inversión, tecnología y capacitación, y esto es algo que los campesinos no están dispuestos y tampoco pueden realizar por sí solos. No obstante, tal como lo menciona Pérez-Vitoria (2010), a pesar de que la modernización y la agroindustria han intentado "asesinar al campesino", esto está lejos de cumplirse, puesto que en todo el mundo se encuentran lugares de resistencia que son testigos de la vitalidad del mundo rural, y el campesino de Chipaque es un reflejo de esta situación. Es precisamente esta resistencia la que nos permite plantear racionalidades alternativas para generar un desarrollo rural real e integral que esté articulado con el contexto socioeconómico, ambiental y moral de la población.

\section{Referencias}

Abel, A., y Bernanke, B. (2004). Macroeconomía. Madrid: Pearson.

Acevedo-Osorio, A\#., y Marti\#nez-Collazos, J. (comps.). (2016). La agricultura familiar en Colombia. Estudios de caso desde la multifuncionalidad y su aporte a la paz. Bogota\#: Ediciones Universidad Cooperativa de Colombia.

Akram-Lodhi, A. H. (2000). A bitter pill? Peasants and sugarcane markets in northern Paskistan. European Journal of Development Research, I2(I), 206-228. https://www.doi.org/I0.1080/09578810008426759

Beltrán, S. R. (2016). La institucionalidad rural en Colombia: reflexiones para su análisis y fortalecimiento. Mundo Agrario, 17(35). Recuperado de https://www.mundoagrario.unlp.edu.ar/article/view/MAe022/7420

Berdegué, J. A., Carriazo, F., Jara, B., Modrego, F., y Soloaga, I. (2015). Cities, territories, and inclusive growth: Unraveling urban-rural linkages in Chile, Colombia, and Mexico. World Development, 73, 56-71. https://w ww.doi.org/10.1016/j.worlddev.2014.12.013

Bernal, C. A. (2007). Introduccio\#n a la administracio\#n de las organizaciones. Un enfoque global e integral. México: Pearson Educación.

Bu\#yu\#ko\#zkan, G., Feyzioglu, O., y Nebol, E. (2008). Selection on the strategic alliance partner in logistics value chain. International Journal of Production Economics, II3(I), I48-158. https://www.doi.org/I0.I0I6/j.ijpe.20 07.01 .016

Chayanov, A. (1981). La organización de la unidad económica campesina. Buenos Aires: Nueva Visión.

Chonchol, J. (1990). Modernización agrícola y estrategias campesinas en América Latina. Revista Internacional de Ciencias Sociales. El Campesinado. Estrategias Campesinas, Políticas Estatales y Fuerzas del Mercado, (I24), I43-I60. Recuperado de https://www.unesdoc.unesco.org/images/0008/000882/088275so.pdf

Collantes, J. C. A. (2018). Agricultura ecológica y de proximidad como herramienta para el desarrollo rural: el ejemplo de San Sebastián (España). Ager: Revista de Estudios sobre Despoblación y Desarrollo Rural, (24), 19I-244. Recuperado de https://www.dialnet.unirioja.es/servlet/articulo?codigo=6399269

Dietmar, S., Donovan, J., Fisk, J., y Muldoon, M. F. (20I2). Value chain development for rural poverty reduction: A reality check and a warning. Enterprise Development and Microfinance, $23(\mathrm{I}), 54-69$.

Dubbeling, M., Santini, G., Renting, H., Taguchi, M., Lançon, L., Zuluaga, J., ... Andino, V. (2017). Assessing and planning sustainable city region food systems: Insights from two Latin American cities. Sustainability (Switzerland), 9(8). https://www.doi.org/10.3390/su9081455

Ellis, F. (2000). The determinants of rural livelihood diversification in developing countries. Journal of Agricultural Economics, 5I(2), 289-302. https://www.doi.org/I0.IIII/j.I477-9552.2000.tboI229.x

Escobar, A. (2007). La invención del tercer mundo. Construcción y deconstrucción. Caracas: El Perro y la Rana. 
Fajardo, D., Machado, A., Gómez Villa, P., Salazar, M. C., Zamosc, L., y Gaitán de Pombo, M. del P. (198I). Campesinado y capitalismo en Colombia. Bogotá: Cinep.

Forero, J. (1999). Economía y sociedad rural en los Andes colombianos. Bogotá: Pontificia Universidad Javeriana. Forero, J. (2002). La economía campesina colombiana, 1990-200I. Cuadernos Tierra y Justicia, (2).

Guber, R. (200I). La etnografía: método, campo y reflexividad. Bogotá: Norma.

Harvey, D. (1990). La condición de la posmodernidad: investigación sobre los orígenes del cambio cultural. Buenos Aires: Amorrortu.

Instituto Geográfico Agustín Codazzi (IGAC). (1998). Mapa. Ubicación del municipio de Chipaque en Cundinamarca. Bogotá: autor.

Instituto Geográfico Agustín Codazzi (IGAC). (1999). Esquema de ordenamiento territorial. Documento diagnóstico. Municipio de Chipaque, Cundinamarca. Bogotá: autor.

Jaffee, S., y Henson, S. (2005). Agro-food exports from developing countries: The challenges posed by standards. En A. M. Aksoy y J. C. Beghin (eds.), Global agricultural trade and developing countries (pp. 9I-II4). Washington: Banco Mundial.

Kalmanovitz, S., y López, E. (2006). La agricultura colombiana en el siglo XX. Bogotá: Fondo de Cultura Económica.

Kaplinsky, R., y Morris, M. (2000). A handbook for value chain research. International Development Research Centre (IDRC). Recuperado de https://www.prism.uct.ac.za/papers/vchnovor.pdf

Landini, F. (20II). Racionalidad económica campesina. Mundo Agrario, I2(23). Recuperado de https://www.sciel o.org.ar/scielo.php?script=sci_arttext\&pid=S1515-599420110002000 $14 \& \operatorname{lng}=e s \& t \operatorname{lng}=e s$

Machado, A. (1991). Apertura económica y economía campesina. Bogotá: Siglo XXI.

Machado, A. (2017). El problema de la tierra. Conflicto y desarrollo en Colombia. Bogotá: Taurus.

Mankiw, G. N. (20I2). Principios de economía (6.a ed.). Madrid: Paraninfo.

Marsden, T. K., Banks, J., y Bristow, G. (2000). Food supply chain approaches: Exploring their role in rural development. Sociologia Ruralis, $40(4)$, 424-438. https://www.doi.org/I0.IIII/I467-9523.00158

Mayer, E. (1999). Campesinos y neoliberalismo. Discusión sobre la teoría económica del campesinado con énfasis en el medio andino. Recuperado de https://www.red.pucp.edu.pe/wp-content/uploads/biblioteca/r60210.p $\mathrm{df}$

Meji\#a, C. A. (2005). Me\#todos para la determinacio\#n de precios. Documentos Planning. Recuperado de https ://www.planning.com.co/bd/mercadeo_eficaz/Agosto2005.pdf

Mitchell, J., Keane, K., y Coles, C. (2009). Trading up: How a value chain approach can benefit the rural poor. Londres: Comercio y Pobreza en Latinoamérica (Copla), Overseas Development Insititute (ODI).

Municipio de Chipaque. (20I2). Alcaldía Municipal de Chipaque. Recuperado de https://www.chipaque-cundi namarca.gov.co

Organización de las Naciones Unidas para la Alimentación y la Agricultura [FAO]. (2015). The state of agricultural commodity markets 2015-2016. Value chains, agricultural markets and food security. Recuperado de https:/ /www.fao.org/3/a-i5226e.pdf

Pérez-Vitoria, S. (20ro). El retorno de los campesinos. Una oportunidad para nuestra supervivencia. Barcelona: Icaria.

Ploeg, J. van der. (2010). Nuevos campesinos. Campesinos e imperios alimentarios. Barcelona: Icaria. 
Polanyi, K. (1982). La gran transformación. Los orígenes políticos y económicos de nuestro tiempo. Madrid: Fondo de Cultura Económica.

Red de Agroindustria Rural (Redar). (199I). Deshidratación de frutas y hortalizas [cartilla impresa]. Cuadernos de Agroindustria Rural. Serie deshidratados.

Scott, J. (1976). The moral economy of the peasant: Rebellion and subsistence in Southeast Asia. New Haven: Yale University Press.

Seligmann, L. (1989). To be in between: The Cholas as market women. Comparative Studies in Society and History, 3I(4), 694-72I. Recuperado de https://www.jstor.org/stable/I79075?seq=I\#page_scan_tab_contents

Shiva, V. (2013). Making peace with the earth. Nueva York: Pluto Press.

Swinnen, J., y Maertens, M. (2007). Globalization, privatization, and vertical coordination in food value chains in developing and transition countries. Agricultural Economics, 37(2), 89-102. https://www.doi.org/I0.IIII/ j.1574-0862.2007.00237.x

Thompson, E. P. (1971). The moral economy of the English crowd in the i8th century. Past \& Present, (50), 76-136. Recuperado de https://www.brh.org.uk/site/book-reviews/the-moral-economy-of-the-english-crowd-in-theI8th-century/

Tobasura, I. (20II). De campesinos a empresarios: la reto\#rica neoliberal de la poli\#tica agraria en Colombia. Espacio Abierto: Cuaderno Venezolano de Sociologi\#a, 20(4), 64I-647. Recuperado de https://www.redalyc .org/articulo.oa?id=I2220531005

Vélez, L. D. (2015). Adaptabilidad y persistencia de las formas de producción campesinas. Bogotá: Universidad Nacional de Colombia.

Webber, C. M., y Labaste, P. (2010). Building competitiveness in Africa’s agriculture: A guide to value chain concepts and applications. Washington: Banco Mundial.

Wolf, E. (1966). Peasants. Nueva Jersey: Prentice Hall.

\section{Notas}

* Artículo de investigación

Licencia Creative Commons CC BY-4.० 